\title{
Mineral and bone disorders secondary to chronic kidney disease (renal osteodystrophy)
}

\author{
Alphonsus N. Onyiriuka', Olubunmi B. Fakeye-Udeogu' ${ }^{1}$, Mohammad Abdullahi', Chiedozie J. \\ Achonwa', Isaac O. Oluwayemi' ${ }^{1}$, Moustafa Kouyate ${ }^{1}$, Abiola O. Oduwole ${ }^{2}$, Elizabeth E. Oyenusi ${ }^{2}$
}

Sri Lanka Journal of Diabetes, Endocrinology and Metabolism 2015; 5: 91-94

\begin{abstract}
Chronic kidney disease (CKD) in paediatric population gives rise to complex of diseases that is known as chronic kidney disease-mineral and bone disorder (CKD-MBD), which mainly involves the calcium and bone metabolism. Associated rickets and secondary hperparathyroidism leads to pathological changes in the growing bone causing deformities, pathological fractures and growth retardation leading to poor quality of life. Early recognition and proper management can minimize these effects and this care highlights the importance of early diagnosis of proper treatment of CKD in paediatric population.
\end{abstract}

Key words: chronic kidney disease, mineral-bone disorders, secondary hyperparathyroidism, pathological fracture, renal osteodystrophy.

\section{Introduction}

Metabolic bone diseases are those disorders of the skeleton associated with alteration in calcium and phosphorus homeostasis. It is a common complication of chronic kidney disease (CKD), representing part of a broad spectrum of disorders of mineral metabolism that occurs in this clinical setting (1). Chronic kidney disease-mineral and bone disorder (CKD-MBD) is defined as a systemic disorder of mineral and bone metabolism due to $\mathrm{CKD}$ that is manifested by either one or a combination of the following: abnormalities of calcium, phosphorus, parathyroid hormone (PTH) and vitamin D metabolism, abnormalities of bone-turnover, mineralization, volume, linear growth and strength, vascular or soft tissue calcification (2). In contrast, the term "renal osteodystrophy" describes the pathological changes that are seen in bone structure in $\mathrm{CKD}$, but fails to describe adequately the adverse changes in mineral and hormonal metabolism that have grave consequences for patient survival. Renal osteodytrophy currently refers specifically to the different bone lesions defined by bone histomorphometry (3) and is therefore, only one aspect of CKD-MBD (4). Such bone lesions include osteitis fibrosa cystica, osteomalacia, dynamic bone disease, mild hyperparathyroidism related bone disease and mixed uraemic osteodystrophy (5).

The kidney is mainly responsible for calcium, phosphorus, magnesium and acid-base balance. It is also the organ responsible for synthesizing active vitamin D, 1,25dihydoxycholecalceferol $(1,25(\mathrm{OH}) 2 \mathrm{D} 3)$ that is needed for calcium regulation in the body (6). With progressive loss of actual or functional renal tissue, there is a decline in renal $1 \alpha$-hydroxylase activity, resulting in decreased production of $1,25(\mathrm{OH}) 2 \mathrm{D} 3$, which in turn leads to impaired intestinal absorption of calcium and hypocalcaemia (5). The resultant hypocalcaemia is a strong stimulus for PTH secretion leading to secondary hyperparathyroidism (1). The progressive renal insufficiency also cause phosphate retention that gives rise to hyperphosphatemia, which further promotes hypocalcaemia and increased PTH secretion leading to a highturnover bone disease $(1,7)$. CKD-MBD is a result of secondary hyperparathyroidism that developed in chronic renal disease due to the reduction in $1,25(\mathrm{OH})_{2}$ D3 level and phosphate retention.

The impact of CKD-MBD in children may be immediate and it will manifest as a disequilibrium in calcium, phosphorus, and vitamin D metabolism determinants. It has delayed effects such as growth retardation, deformities, fractures, vascular/tissue calcifications that ultimately leads to increased morbidity and mortality and poor quality of life $(3,7,8)$. It is estimated that the incidence of clinical or radiographic manifestation of bone disease in children with CKD range from $41 \%$ to $68 \%(9,10)$, depending on the age of onset and the stage of CKD. In a

${ }^{1}$ Paediatric endocrinology training centre for West Africa, Department of paediatrics, Lagos university teaching hospital, PMB 12003, Lagos, Nigeria, ${ }^{2}$ Department of paediatrics, Faculty of clinical sciences, college of medicine, university of Lagos, PMB 12003, Lagos, Nigeria. 
10 year follow-up of 50 children with chronic renal failure, Hsu et al (10) has reported that 34 (68\%) developed radiological evidence of bone disease. In a cohort of 249 young Dutch adults with onset of end stage renal disease before the age of 14 years, $61 \%$ had severe growth retardation, $37 \%$ severe bone disease and $18 \%$ disabilities resulting from bone impairment (11). The evidence suggests that CKD-MBD is a common clinical problem in pediatric practice but is probably under-diagnosed in poor resource settings. The purpose of this case report is to increase the alertness of child health physicians to occurrence of mineral and metabolic bone disease as a complication of CKD in children, thereby encouraging early institution of preventive measures.

\section{Case report}

An eight-year old Nigerian boy presented to the Lagos University Teaching Hospital (LUTH) with a history of poor growth, swelling of the wrists and ankles with bone pain for 3 years and inability to walk for 2 weeks. He was the shortest among his classmates and also the shortest in his family. His 4 year old younger brother was taller than him. The swelling of his wrists and ankles had increased in size with time and he had also developed bone pain, which became worse about 4 weeks before presentation. Along with the pain, he had developed inability to walk that his mother had to seek medical advice. His early childhood was unremarkable except for a posterior urethral valve ablation done at the age of 4 months when presented with poor urinary stream.

His height, weight and arm span were 90 cm (-6.7 SDS), $13 \mathrm{~kg}(-2.4 \mathrm{SDS})$ and $100 \mathrm{~cm}$. His upper- to-lower segment ratio was 1.2:1. He had genu valgum deformity with anterior convexity of tibia/fibula (Figure 1). He had widening of the wrists and ankles (Figure 2, 3), Rachitic rosary and bossing of the skull suggesting the clinical possibility of Rickets.

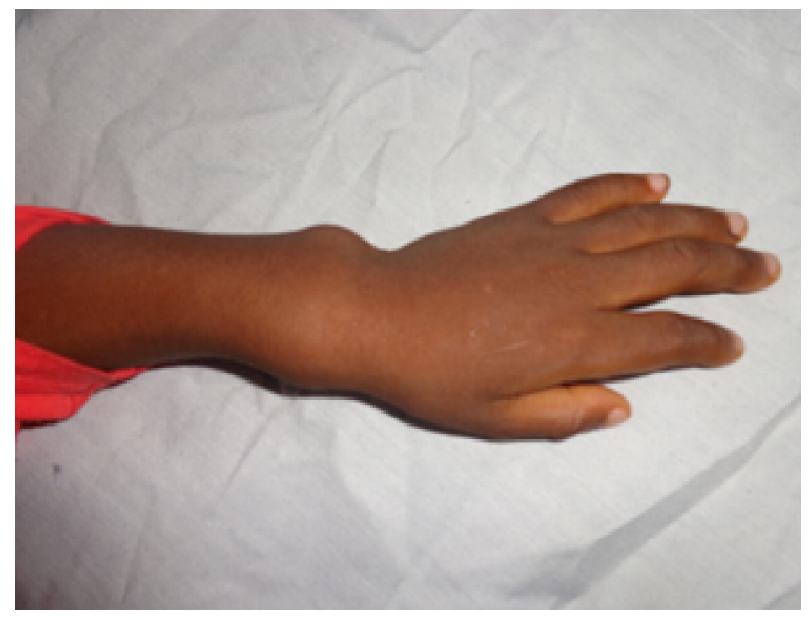

Figure 1. Widening of the wrist.

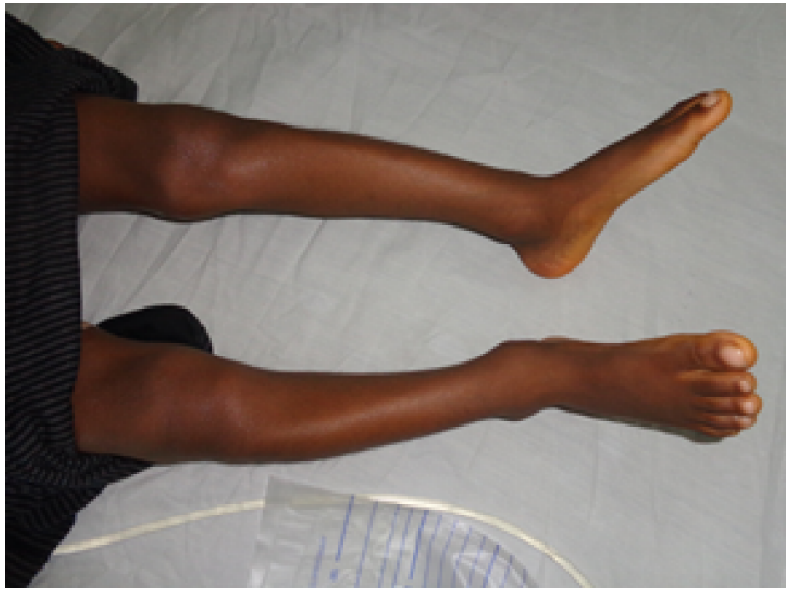

\section{Figure 2. Widening of the ankles and} deformities of the lower limbs.

Urinalysis revealed proteinuria and his hemoglobin level was $11.5 \mathrm{~g} / \mathrm{dl}$ (Packed Cell Volume 35\%). The micturating cystourethrogram (MCUG) showed moderate dilatation of the posterior urethra and well distended urinary bladder with sacculations on the wall suggestive of posterior urethral valve. His biochemical investigations showed evidence of renal impairment and hypocalcaemia (Table 1). His X-rays of hands and pelvis showed evidence of rickets and pathological fractures in both femurs (Figure 3).

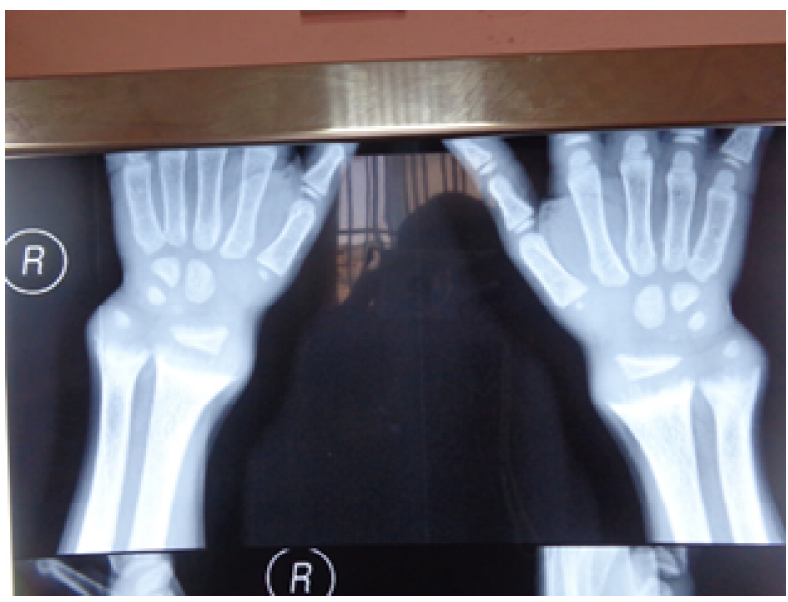

Figure 3. Cupping and fraying epiphyseal bones.

\section{Discussion}

A biochemical assessment of disorders of bone and mineral metabolism is the mainstay of diagnosis and treatment of CKD-MBD (12). However, the National Kidney Foundation [Kidney Disease Outcomes Quality 
Table 1. Summary of laboratory findings

\begin{tabular}{lll}
\hline Laboratory parameter & Results & Comments \\
\hline Serum Sodium & $130 \mathrm{mmol} / \mathrm{L}$ & Mildly low \\
Serum potassium & $3.7 \mathrm{mmol} / \mathrm{L}$ & Normal \\
Serum chloride & $101 \mathrm{mmol} / \mathrm{L}$ & High normal \\
Serum bicarbonate & $15.0 \mathrm{mmol} / \mathrm{L}$ & Very low \\
Serum urea & $13.3 \mathrm{mmol} / \mathrm{L}$ & High \\
Serum creatinine & $284.5 \mu \mathrm{mol} / \mathrm{L}$ & Very high \\
Serum calcium (total) & 1.78 & Low \\
$\begin{array}{l}\text { Serum albumin } \\
\text { Serum phosphate }\end{array}$ & $38 \mathrm{~g} / \mathrm{dl}$ & Normal \\
\hline $\begin{array}{l}\text { Serum alkaline } \\
\text { phosphatase }\end{array}$ & $1600 \mathrm{~mm} / \mathrm{L}$ & Upper limit \\
Serum parathyroid & & of normal \\
hormone (PTH) & $90 \mathrm{pmol} / \mathrm{L}$ & Very high \\
Urine output & $6 \mathrm{ml} / \mathrm{kg} / \mathrm{hr}$ & Polyuria \\
Urine calcium & $<0.5 \mathrm{mmol} / \mathrm{L}$ & Low \\
Urine creatinine & $1.6 \mathrm{mmol} / \mathrm{L}$ & High \\
$\begin{array}{l}\text { Urine calcium:urine } \\
\text { creatinine ratio }\end{array}$ & 0.31 & Low \\
Urine culture & $\mathrm{No} \mathrm{growth}$ & Sterile \\
Egfr & $19 \mathrm{ml} / \mathrm{min} / 1.73 \mathrm{~m}^{2}$ & Very low \\
\hline
\end{tabular}

$\mathrm{eGFR}=$ Estimated glomerular filtration rate

Initiative (KDOQI) Guidelines] suggests that a bone biopsy should be considered in all patients with CKD who have pathological fractures (13). This is similar to the position statement from Kidney Disease: Improving Global Outcome (KDIGO) foundation (2). Although we could not perform bone biopsy in this patient, there was enough biochemical and radiological evidence to suggest the diagnosis of CKD-MBD with increased bone remodeling in our index patient.

In CKD-MBD, hyperphosphataemia is an expected biochemical abnormality. However, the serum phosphate level was just at the upper limit of normal reference range in our patient. It is well established that serum phosphate tend to fall with increasing serum PTH concentration primarily as a result of increasing renal phosphate wasting (14) and this could be the possible explanation for high normal phosphate levels in our patient.

The index patient had bilateral pathological fractures of the femurs at the time presentation, implying that he had pre-dialysis fracture. This finding strongly challenges the general belief, as documented in the literature, which fractures do not occur until the patient is placed on dialysis (13). A review of the literature indicated that the degree of linear growth retardation varies with the stage of $\mathrm{CKD}$ as follows: - 1 SDS in mild, -1.5 SDS in moderate and -1.8 SDS in severe CKD (15). Anemia, metabolic acidosis, secondary hyperparathyroidism, water and electrolyte disturbances, uremia and renal osteodystrophy are probable causes for the linear growth retardation in CKD. All these factors may have contributed to the linear growth retardation in our patient.

In the management of CKD-MBD, we mainly focused on 3 areas: (I) to provide an optimal nutritional support to maximize the final height and avoid bone deformities, (ii) to equilibrate calcium/phosphate metabolism; so as to provide acceptable bone quality and cardiovascular status and (iii) to control all metabolic and clinical abnormalities that can worsen bone and (mainly) growth, metabolic acidosis, anemia, malnutrition and $25(\mathrm{OH})$ vitamin $\mathrm{D}$ deficiency (16). Monitoring treatment is also important, as over treatment can leads to dynamic bone disease, growth failure, hypercalcaemia and progression of cardiovascular calcification (16). In this regard, determination of the target PTH level is essential in order to assess the success of the therapy. However, the target PTH level still remains debatable (3). In this context, it is currently recommended to monitor growth and phosphorus/calcium $/ 25(\mathrm{OH})$ vitamin $\mathrm{D}$ levels as primary targets in the management of CKD-MBD in children (3). Newer therapeutic agents such as calcimimetic, phosphate-binding agents (Lanthanum carbonate) and vitamin $\mathrm{D}$ analogues may suppress serum PTH levels effectively while limiting intestinal calcium absorption and skeletal fibroblast growth factor 23 (FGF 23) stimulation (16). After correcting all metabolic abnormalities, the use of supraphysiological dose of recombinant human growth hormone (rhGH) has been shown to be safe and effective in increasing growth and final adult height of these patients $(17,18)$. These strategies represent the future therapeutic alternatives in the management of CKD in paediatric age group.

In conclusion, all children with CKD should be evaluated early in the course of the disease for the presence of a metabolic bone disorder with the aim of putting in place preventive strategies.

\section{References}

1. Martin KJ, Gonzalez EA. Pathophysiology of renal osteodystrophy. Clin Reviews Bone Mineral Metabolism 2007; 5(1): 11-19.

2. Moe S, Drueke T, Cunningham J, Goodman W, Martin K, Olgaard K, Ott S, Sprague S, Lameire N, Eknoyam G. Definition, evaluation and classification of renal osteodystrophy: A position statement from Kidney Disease: Improving Global Outcomes (KDIGO). Kidney Int 2006; 69: 1945-53. 
3. Bacchetta J, Harambart J, Cohat P, Salusky IB, WesselingPerry K. The consequences of chronic kidney disease on bone metabolism and growth in children. Nephrol Dial Transplant 2012; 27; 3063-71.

4. Wesseling K, Bakkaloglu S, Salusky I. Chronic kidney disease mineral and bone disorder in children. Pediatr Nephrol 2008; 23: 195-207.

5. Tomasello S. Secondary hyperparathyroidism and chronic kidney disease. Diabetes Spectrum 2008; 21(1): 19-25.

6. Simckes AM, Warady BA. Chronic renal failure in children. In: Nammalwar BR, Vijayakumar M eds. Principles and Practice of Pediatric Nephrology. New Delhi, Jaypee Brothers Medical Publishers Ltd 2004; 2: 233-44.

7. Wesseling-Perry K, Salusky IB. Chronic kidney disease: mineral and bone disorder in children. SeminNephrol 2013; 33(2): 169-79.

8. Hruska KA, Choi ET, Memon I et al. Cardiovascular risk in chronic kidney disease (CKD): the CKD-mineral bone disorder (CKD-MBD). PediatrNephrol 2010; 25: 769-78.

9. Potter DE, Wilson CJ, Ozonoff MB. Hyperparathyroidism bone disease in children undergoing long-term hemodialysis: Treatment with vitamin D. J Pediatr 1974; 85; 60.

10. Hsu AC, Kooh SW, Fraser D, Cummings WA, Fornasier VL. Renal osteodystrophy in children with chronic kidney failure: An unexpectedly common and incapacitating complication. Pediatrics 1982; 70(5): 742-50.

11. Groothoff JW, Offinga M, Van Eck-Smit BL et al. Severe bone disease and low bone mineral density after juvenile renal failure. Kidney Int 2003; 63: 266-75.

12. Martin KJ, Gonzalez EA. Metabolic bone disease in chronic kidney disease. J Am SocNephrol 2007; 18: 875-85.

13. National Kidney Foundation. Kidney Disease Outcomes Quality Initiative clinical practice guidelines for bone metabolism and disease in children with chronic kidney disease. Am J Kidney Dis 2005; 46(1, 4); 1-121

14. Heller HJ. Calcium homeostasis. In: Griffin JE, Ojeda SR eds. Textbook of Endocrine Physiology, New York, Oxford University Press 2004; 5; 349-76.

15. North American Pediatric Renal Transplant Cooperative (2006). North American Pediatric Renal Transplant Cooperative Study (NAPRTCS), 2006 Annual Report

16. Chauhan V, Kelepouris E, Chauhan N, Vaid M. Current concepts and management strategies in chronic kidney disease-mineral and bone disorder. South Med J2012; 105(9): 479-85.

17. Haffner D, Schaefer F, Nissel R, et al. Effect of growth hormone treatment on adult height of children with chronic kidney failure: German study group for growth hormone treatment in chronic renal failure. $N$ Engl J Med 2000; 343: 923-30.

18. Kidney Disease Outcomes Quality Initiative (KDOQI). Clinical practice guidelines for bone metabolism and disease in children with chronic kidney disease. Am J Kidney Dis 2005; 46(1); 122. 